\title{
Role of Patient Factors, Preferences, and Distrust in Health Care and Access to Liver Transplantation and Organ Donation
}

\author{
Julius M. Wilder, ${ }^{1,2 *}$ Omobonike O. Oloruntoba, ${ }^{1 *}$ Andrew J. Muir, ${ }^{1,2}$ and Cynthia A. Moylan ${ }^{1,3}$ \\ ${ }^{1}$ Division of Gastroenterology, Duke University Medical Center, Durham, NC; ${ }^{2}$ Duke Clinical Research Institute, Durham, NC; \\ ${ }^{3}$ Department of Medicine, Durham Veterans Affairs Medical Center, Durham, NC
}

\begin{abstract}
Despite major improvements in access to liver transplantation (LT), disparities remain. Little is known about how distrust in medical care, patient preferences, and the origins shaping those preferences contribute to differences surrounding access. We performed a single-center, cross-sectional survey of adults with end-stage liver disease and compared responses between LT listed and nonlisted patients as well as by race. Questionnaires were administered to 109 patients (72 nonlisted; 37 listed) to assess demographics, health care system distrust (HCSD), religiosity, and factors influencing LT and organ donation (OD). We found that neither HCSD nor religiosity explained differences in access to LT in our population. Listed patients attained higher education levels and were more likely to be insured privately. This was also the case for white versus black patients. All patients reported wanting LT if recommended. However, nonlisted patients were significantly less likely to have discussed LT with their physician or to be referred to a transplant center. They were also much less likely to understand the process of LT. Fewer blacks were referred $(44.4 \%$ versus $69.7 \% ; P=0.03)$ or went to the transplant center if referred $(44.4 \%$ versus $71.1 \% ; P=0.02)$. Fewer black patients felt that minorities had as equal access to LT as whites $(29.6 \%$ versus $57.3 \% ; P<$ 0.001). For OD, there were more significant differences in preferences by race than listing status. More whites indicated OD status on their driver's license, and more blacks were likely to become an organ donor if approached by someone of the same cultural or ethnic background $(P<0.01)$. In conclusion, our analysis demonstrates persistent barriers to LT and OD. With improved patient and provider education and communication, many of these disparities could be successfully overcome.
\end{abstract}

Liver Transplantation 22 895-905 2016 AASLD.

Received October 15, 2015; accepted March 10, 2016.

\section{SEE EDITORIAL ON PAGE 881}

Approximately 600,000 adults suffer from liver cirrhosis in the United States. ${ }^{(1)}$ Liver transplantation (LT) is

Abbreviations: CI, confidence interval; DRI, Duke religious index; ESLD, end-stage liver disease; HCSD, Health Care System Distrust; ICD-9, International Classification of Diseases, Ninth Revision; $I Q R$, interquartile range; $L T$, liver transplantation; $M E L D$, Model for End-Stage Liver Disease; NIDDK, National Institute of Diabetes and Digestive and Kidney Diseases; OD, organ donation; $O R$, odds ratio; $S D$, standard deviation.

Address reprint requests to Cynthia A. Moylan, M.D., M.H.S., Division of Gastroenterology, Duke University Medical Center, 905 South LaSalle Street, DUMC 3256, GSRB1, Durbam, NC 27710. Telephone: 919-668-0401; FAX: 919-684-4183; E-mail: cynthia.moylan@duke.edu a lifesaving treatment option for the subset of patients who progress to end-stage liver disease (ESLD). LT is associated with increased life expectancy with more than $70 \%$ of patients surviving at least 5 years and many surviving more than 10 years. ${ }^{(2)}$ Despite this, only a small fraction of patients with ESLD are ever successfully listed for LT, an essential step toward receiving a liver allographt. Although improvements in the process of listing and receipt of a liver organ followed the adoption of the Model for End-Stage Liver Disease (MELD) score in 2002 and subsequent adjustments for serum sodium and improved organ sharing, many barriers continue to exist.

Obstacles to successful LT include geographic location, insurance, income status, gender, and race. ${ }^{(3)}$ Many of these have been well documented. For example, female patients experience lower rates of evaluation and listing for LT as well as significantly lower LT rates overall. ${ }^{(4-7)}$ African Americans are significantly 
less likely to be referred for LT, are underrepresented on the LT waiting list, and are listed at more advanced stages of disease. ${ }^{(5,7,8)}$ Geography and relative organ availability have also been shown to contribute to disparities in LT for Hispanics. ${ }^{(9)}$ Equal access to LT requires improved understanding of how various potentially influential factors such as patient preference, cultural and religious beliefs, and referral patterns contribute to listing and receipt of a LT as well. ${ }^{(10)}$

These types of influences can be difficult to study and thus, little is known about their impact on access to LT. Existing data suggest that many play important roles in why certain patients get evaluated and listed for LT whereas others never do. ${ }^{(2,4,11)}$ Patient preferences for medical care and the origins shaping those preferences may lend insight into key disparities surrounding access to LT. Religious beliefs, expectations of care, trust of the medical community, and awareness about LT and organ donation (OD) influence preferences and likely contribute to systematic differences by race, gender, and/or ethnicity. Evidence for these effects exists outside of the LT literature. For example, Ayanian et al. ${ }^{(12)}$ found black patients less likely to want renal transplantation while on dialysis than whites. Similarly, black patients in the Coronary Artery Surgery Study were less likely to undergo coronary artery bypass grafting even when physicians recommended this procedure over medical management as compared to whites. ${ }^{(13)}$ Very little information exists regarding the impact of patient preferences and expectations of care on access to LT. The objectives of this study were to characterize patient preferences and patient-perceived concerns about LT and to determine the influence of race on the variables that shape those preferences.

*These authors contributed equally to this work.

Julius M. Wilder was supported in part by the Duke University National Institute of Diabetes and Digestive and Kidney Diseases (NIDDK) T32 Training Grant No. 5T32-DK7568-22. Cynthia A. Moylan was supported in part by the Duke University NIDDK T32 training grant 5T32-DK007568-19 and has received support from the American College of Gastroenterology and Taiwan Pharmaceuticals.

Copyright $(02016$ by the American Association for the Study of Liver Diseases.

View this article online at wileyonlinelibrary.com.

DOI 10.1002/lt.24452

Potential conflict of interest: Dr. Moylan received grants from Taiwan Pharmaceuticals.

\section{Patients and Methods}

\section{STUDY POPULATION}

We conducted a cross-sectional, descriptive survey of patients with ESLD at a large academic medical center. The survey was conducted in 2 cohorts of patients: those with ESLD and an indication for LT who were not yet listed ("nonlisted") and those listed for LT as identified by the United Network for Organ Sharing LT waiting list ("listed"). Eligibility criteria for all participants included residing in 1 of 31 local North Carolina counties (see Supporting Table 1), being age 18 years and older, and having the ability to speak and understand English. Nonlisted patients were considered LT eligible patients meeting minimal wait-listing criteria including cirrhosis with a complication of ESLD and/or MELD score greater than 12, or hepatocellular carcinoma within Milan criteria. ${ }^{(14)}$ We first identified nonlisted patients using the following International Classification of Diseases, Ninth Revision (ICD-9) codes: alcoholic cirrhosis (571.2), chronic hepatitis C virus infection (070.54), nonalcoholic cirrhosis (571.5), esophageal varices $(456.0,456.1,456.2)$, hepatic coma (572.2), ascites (789.5), spontaneous bacterial peritonitis (567.23), biliary cirrhosis (571.6), and hepatocellular carcinoma (155.0). Medical records were then reviewed for a diagnosis of cirrhosis and decompensating events other than those identified by ICD-9 codes and on liver biopsy as well as for MELD scores greater than 12. We excluded patients based on the current relative exclusion criteria used at our center during the time frame under study. These included all patients aged 72 years and older, those with malignancies precluding transplantation, and those with acquired immunodeficiency syndrome. We also excluded nonlisted patients who previously received LT or other organ transplantation. Patients with acute hepatic failure were not excluded, but the ICD-9 code for acute hepatic failure (570) was not used to identify patients. Patients meeting all criteria were contacted through their primary provider via an introductory letter and then via telephone call or in clinic. If patients agreed to participation, they were included in the study between June 1, 2007 and June 13, 2008 and September 1, 2012 and October 1, 2013 (see Supporting Materials).

\section{SURVEY DESIGN AND DATA COLLECTION}

All patients completed a study survey after providing informed consent. Trained personnel administered the survey in person or via telephone using a script 
approved by the institutional review board. Consent for patients with signs of hepatic encephalopathy was obtained using a legally authorized representative approved by the institutional review board. Because access to LT involves many steps that may be influenced by a patient's attitudes and behaviors, the survey questionnaire was developed to assess where barriers might arise. As such, it was divided into 5 sections:

1. Patient sociodemographics.

2. Religious beliefs/Duke religious index (DRI).

3. Preferences and understanding of LT.

4. Health Care System Distrust scale.

5. Preferences regarding OD.

The survey included questions regarding sociodemographics influencing access to LT such as marital status, employment, education level, insurance, and transportation method. The survey assessed the patient's understanding and preferences regarding LT and OD as well as factors that could influence those attitudes such as concerns regarding the financial costs, expectations about improved quality of life and life expectancy, and whether or not they were ever seen by a hepatologist.

Trust in the medical system may impact patient preferences and access to LT. In order to capture this information, we used the previously validated 10 -item Health Care System Distrust (HCSD) scale to evaluate differences in distrust between the 2 groups and by race. The distrust scale encompasses beliefs about honesty, motives, and equity of the health care system and includes items such as "The health care system cares more about holding costs down than it does about doing what is needed for my health" and "If a mistake were made in my health care, the health care system would try to hide it from me." The HCSD scale is scored on a 5-point Likert scale and ranges from 10 to 50 with lower scores associated with more distrust. ${ }^{(15)}$ Similarly, religious beliefs may influence a patient's desire for LT and OD. We used the DRI, a validated 5-item scale capturing 3 major dimensions of religiousness (public-organizational, private-nonorganizational, and intrinsic religiosity) to examine whether religiousness differed by LT listing and by race. ${ }^{(16)}$ Scores range from 6 to 30 with higher scores indicating greater religiousness/spirituality (see Supporting Table 2).

\section{STATISTICAL ANALYSES}

The primary objective was to evaluate whether attitudes and preferences regarding LT differed among patients already listed for LT (listed) and those with
ESLD and an indication for LT but not yet listed (nonlisted). Initial assessment was based on HCSD via the HCSD scale. We then evaluated the impact of differences in sociodemographic characteristics, religiosity via the DRI, patient understanding, and preferences regarding LT and OD by group and by race.

Wilcoxon rank sum test for continuous predictors and chi-square or Fisher's exact tests for categorical variables were used to determine differences between the study groups and by race. Mean values for the HCSD scale were compared by group and by race using $t$ tests as previously described. ${ }^{(15)}$ The DRI was tested between listed and nonlisted patients and by race for the 3 dimensions of religiosity and by the religiosity sum score using Wilcoxon rank sum tests. Multivariate logistic regression modeling with stepwise backward variable selection was performed to determine the association between sociodemographic characteristics and the odds of being listed for LT while controlling for confounders. All variables significant to $P<0.05$ in the univariate analysis were included in the multivariate model and retained at the $P<0.10$ level. All tests of significance were 2 -sided, with a $P$ value $<0.05$ considered significant. All analyses were performed using JMP statistical software, version 11.0.0 (SAS Institute Inc., Cary, NC). Duke University Medical Center (Durham, NC) institutional review board approved all study procedures.

\section{Results}

For this study, 109 patients (72 nonlisted, 37 listed) completed the survey and were included in the final analyses. Of 238 eligible nonlisted subjects, 96 (40.3\%) were successfully contacted and agreed to participation in the study. Seventy-two of the 96 completed the consent and survey and were included in the final analyses. Eighty-nine (37.4\%) could not be reached due to incorrect contact information, 53 (22.3\%) declined participation, and 24 of the 96 who initially agreed did not complete the survey $(6 / 4$ [25\%]) or failed to mail back a correct consent form (18/24, [75\%]). Of 68 eligible listed patients, $40(58.8 \%)$ agreed to participate and 37 of these successfully completed the consent and survey and were included in the final analyses; the other 28 patients declined participation or were unable to be contacted; and 3 agreed but did not return the consent form. In comparing gender and race between patients who declined and those who were eligible nonlisted participants, we found that gender was similar between the groups (50.9\% male [27/53] versus $61.1 \%$ male [44/72]; 
TABLE 1. Summary of the Sociodemographic Characteristics of Listed and Nonlisted Patients in the Study Population

\begin{tabular}{|c|c|c|c|}
\hline & Listed Patients $(n=37)$ & Nonlisted Patients $(n=72)$ & $P$ Value \\
\hline Race & & & 0.02 \\
\hline Caucasian/white & $27(73)$ & $49(68.1)$ & \\
\hline African American/black & $6(16.2)$ & $21(29.2)$ & \\
\hline Asian/Asian American & $3(8.1)$ & 0 & \\
\hline Unknown & $1(2.7)$ & 0 & \\
\hline Multiracial & 0 & $2(2.8)$ & \\
\hline Age, years, median (IQR) & $53(45-59)$ & $58(52-62.8)$ & 0.01 \\
\hline Gender, male & $21(56.8)$ & $44(61.1)$ & 0.7 \\
\hline Education & & & 0.02 \\
\hline Less than a college degree & $19(51.4)$ & $53(73.6)$ & \\
\hline College graduate or greater & $18(48.6)$ & $19(26.4)$ & \\
\hline Average yearly household income ${ }^{\#}$ & & & 0.65 \\
\hline$<\$ 24,999$ & $9(24.4)$ & $26(36.6)$ & \\
\hline$\$ 25,000-\$ 49,999$ & $11(29.7)$ & $19(26.8)$ & \\
\hline$\$ 50,000-\$ 100,000$ & $11(29.7)$ & $18(25.3)$ & \\
\hline$>\$ 100,000$ & $6(16.2)$ & $8(11.3)$ & \\
\hline Primary insurance & & & 0.02 \\
\hline Private/health maintenance organization & $26(70.3)$ & $32(44.4)$ & \\
\hline Government (Medicaid/Medicare)/other/none & $11(29.7)$ & $40(55.6)$ & \\
\hline Employment status & & & 0.03 \\
\hline None & $17(46)$ & $39(54.2)$ & \\
\hline Working full-time & $15(40.5)$ & $13(18)$ & \\
\hline Working part-time & $1(2.7)$ & $1(1.4)$ & \\
\hline Retired & $4(10.8)$ & $19(26.4)$ & \\
\hline Main source of transportation & & & 0.63 \\
\hline Own automobile & $29(78.4)$ & $56(77.8)$ & \\
\hline Family/friend & $8(21.6)$ & $13(18)$ & \\
\hline Public transportation & 0 & $3(4.2)$ & \\
\hline Distance traveled to clinic* & & & 0.39 \\
\hline$<5$ miles & $4(11.1)$ & $3(6.1)$ & \\
\hline 5-20 miles & $6(16.7)$ & $14(28.6)$ & \\
\hline 21-50 miles & $7(19.4)$ & $13(26.5)$ & \\
\hline$>50$ miles & $19(52.8)$ & $19(38.8)$ & \\
\hline
\end{tabular}

NOTE: Data are given as n (\%) unless otherwise noted.

*Missing data for 1 listed and 23 nonlisted patients.

${ }^{\#}$ Missing data for 1 non-listed patient.

$P=0.28)$. There were, however, significantly more black nonlisted participants versus patients who declined (29.2\% [21/72] black, 68.1\% [49/72] white versus 9.4\% [5/53] black, 83.0\% [44/53] white; $P<0.05)$. All enrolled patients were able to complete the survey without assistance of a legally authorized representative.

\section{SOCIODEMOGRAPHIC CHARACTERISTICS}

Study population characteristics are shown in Table 1. The majority of both nonlisted and listed patients were male with nonlisted patients being significantly older than listed patients (58 versus 53 years; $P=0.01$ ). Most were Caucasian/white, nonlisted patients were more likely to be African American/black (29.2\% versus $16.2 \% ; P=0.02$ ), and there were more Asian/ Asian Americans listed. Listed patients reached higher levels of education with significantly more having a college degree or greater $(48.6 \%$ versus $26.4 \% ; P=$ 0.02). Listed patients were also significantly more likely to have private insurance ( $70.3 \%$ versus $44.4 \%$; $P=$ 0.02). Both groups had comparable yearly household incomes, transportation methods, and travel distances to receive clinical care.

We assessed socioeconomic differences by race to determine if variations in preferences by group might be partially explained by race. Supporting Table 3 contains the full table of these results. Although more nonlisted than listed patients were black, this was not statistically significant when comparing the 2 races alone. Whites, however, did have significantly higher education levels than blacks with $42.0 \%$ versus $7.4 \%$ having a college degree or greater $(P<0.001)$. Average yearly household income was also significantly greater in whites with $17.3 \%$ having an income above $\$ 100,000 /$ year. Only $3.7 \%$ of blacks had an income greater than $\$ 100,000 /$ year, while $51.9 \%$ had an 
TABLE 2. Results of the Multivariate Logistic Regression Analysis of Factors Associated With Listing for LT

\begin{tabular}{lccc} 
Characteristic & OR & $95 \% \mathrm{Cl}$ & $P$ Value \\
\hline Age (per unit change) & 0.97 & $0.93-1.01$ & 0.13 \\
Race & 1.40 & $0.44-4.90$ & 0.56 \\
Employment status & 1.77 & $0.60-5.20$ & 0.30 \\
Insurance & 3.11 & $1.27-8.11$ & 0.01 \\
Education & 2.24 & $0.90-5.56$ & 0.08
\end{tabular}

income less than $\$ 24,999 /$ year $(P=0.02)$. Whites were also significantly more likely to have private health insurance and to own their own automobile.

In the multivariate analysis of listing for LT, only insurance status significantly, independently predicted listing for LT after controlling for race, age, education level, and employment status (odds ratio [OR], 3.11; 95\% confidence interval $[\mathrm{CI}], 1.27-8.11 ; P=0.01$; Table 2).

\section{EFFECT OF HCSD}

We hypothesized that distrust in the health care system would impact patient preferences for LT and OD. Interestingly, distrust in the health care system was similar across groups and race. We found no difference in the mean health care distrust between listed and nonlisted patients (34.8 versus $34.2 ; P=0.67$ ) or between whites and blacks (35.0 versus 33.0; $P=0.14$; Table 3). Moreover, the mean scores were higher than the median revealing a preference toward trust in the health care system. Hence, our results suggest that distrust in the health system did not contribute to differences in patient preference or access to LT in our study population.

\section{EFFECT OF RELIGIOSITY}

Similar to health care distrust, we found no significant difference in religiosity between groups or by race. Median DRI scores between the nonlisted and listed patients and by white and black race were nearly identical and indicated a high degree of religiousness/spirituality in our population overall (Table 3). None of the 3 specific components of religiosity differed significantly by group or by race (data not shown).

\section{KNOWLEDGE OF AND PREFERENCES REGARDING LT}

To evaluate how patient knowledge and preferences impacted access to LT, survey questions focused on understanding the process of LT, patterns and preferences regarding the process of referral, and knowledge about wait-listing and liver organ distribution. We expected patients listed for LT to demonstrate a greater knowledge than those not listed for LT, but we wanted to gain a further understanding of where important gaps exist. Not surprisingly, nonlisted patients $(25.4 \%)$ were more likely to report not having or being unsure about having discussed LT with their physician $(P<0.001$; Table 4$)$. Despite having indications for LT, only $47.2 \%$ of nonlisted patients (versus 97.3\% listed) reported being referred to a transplant center $(P<0.001)$. Most referred nonlisted patients reported going to the transplant center. Only 1 patient did not go to the transplant center, but this was because this patient had not yet been to their first appointment. Nonlisted patients were significantly less likely to obtain as much information about LT as desired (65.3\% versus 94.6\%; $P<0.01)$. Significantly fewer nonlisted patients understood the process of distribution of liver organs on the waiting list $47.9 \%$ versus $83.8 \% ; P<0.01)$, the requirements for listing for LT $(41.7 \%$ versus $75.7 \% ; P<0.01)$, or what the MELD score means and includes $(32.0 \%$ versus 81.1\%; $P<0.001)$. Both groups, however, desired a liver transplant if their liver disease was going to shorten their lives and if LT was recommended, and both felt LT would improve their quality of life and expected survival. Financial concerns, diagnostic testing, and travel were not considered barriers to LT for either group.

Racial differences existed in referral to a transplant center in our study. The majority of whites (84\%) and blacks $(81.5 \%)$ endorsed having had a discussion with their physician concerning LT. However, significantly fewer blacks reported being referred to a transplant center $(44.4 \%$ versus $69.7 \% ; P=0.03$ ) or going to the

TABLE 3. HCSD Scale and DRI

\begin{tabular}{|c|c|c|c|c|c|c|}
\hline & \multicolumn{3}{|c|}{ Group } & \multicolumn{3}{|c|}{ Race } \\
\hline & $\begin{array}{l}\text { Listed Patients } \\
\quad(n=37)\end{array}$ & $\begin{array}{c}\text { Nonlisted Patients } \\
\quad(n=72)\end{array}$ & $P$ Value & $\begin{array}{c}\text { White } \\
(n=76)\end{array}$ & $\begin{array}{c}\text { Black } \\
(n=27)\end{array}$ & $P$ Value \\
\hline HCSD scale, mean \pm SD & $34.8 \pm 5$ & $34.2 \pm 6.3$ & 0.67 & $35.0 \pm 5.4$ & $33.0 \pm 7.3$ & 0.14 \\
\hline DRI, median (IQR) & $26(20-28)$ & $25(20-28)$ & 0.83 & $25(20-28)$ & $25(19-28)$ & 0.66 \\
\hline
\end{tabular}

NOTE: HCSD scale, range: 10-50; DRI, range: 6-30. 
TABLE 4. Knowledge and Preferences Regarding LT

\begin{tabular}{|c|c|c|c|c|c|c|}
\hline & \multicolumn{3}{|c|}{ Group } & \multicolumn{3}{|c|}{ Race } \\
\hline & $\begin{array}{l}\text { Listed Patients } \\
\qquad(\mathrm{n}=37)\end{array}$ & $\begin{array}{c}\text { Nonlisted } \\
\text { Patients }(n=72)\end{array}$ & $P$ Value & $\begin{array}{c}\text { White } \\
(n=76)\end{array}$ & $\begin{array}{c}\text { Black } \\
(n=27)\end{array}$ & $P$ Value \\
\hline Has a physician ever discussed LT with you?* & & & $<0.001$ & & & 0.77 \\
\hline Yes & $37(100)$ & $53(74.6)$ & & $63(84)$ & $22(81.5)$ & \\
\hline No/Not sure & $0(0)$ & $18(25.4)$ & & $12(16)$ & $5(18.5)$ & \\
\hline Have you ever been referred to a transplant center? & & & $<0.001$ & & & 0.03 \\
\hline Yes & $36(97.3)$ & $34(47.2)$ & & $53(69.7)$ & $12(44.4)$ & \\
\hline No & $1(2.7)$ & $37(51.4)$ & & $22(29.0)$ & $15(55.6)$ & \\
\hline Not sure & $0(0)$ & $1(1.4)$ & & $1(1.3)$ & $0(0)$ & \\
\hline If you were referred to a transplant center, did you go? & & & $<0.001$ & & & 0.02 \\
\hline Yes & $36(97.3)$ & $35(48.6)$ & & $54(71.1)$ & $12(44.4)$ & \\
\hline No & $0(0)$ & $1(1.4)$ & & $0(0)$ & $1(3.7)$ & \\
\hline Not sure & $0(0)$ & $1(1.4)$ & & $1(1.3)$ & $0(0)$ & \\
\hline Not applicable (ie, not referred) & $1(2.7)$ & $35(48.6)$ & & $21(27.6)$ & $14(51.9)$ & \\
\hline $\begin{array}{l}\text { If liver disease was going to shorten your life } \\
\text { and LT was recommended, would you want one?* }\end{array}$ & & & 0.39 & & & 0.65 \\
\hline Yes & $36(97.3)$ & $65(91.5)$ & & $71(94.7)$ & $25(92.6)$ & \\
\hline No/Not sure & $1(2.7)$ & $6(8.5)$ & & $4(5.3)$ & $2(7.4)$ & \\
\hline $\begin{array}{l}\text { Effect LT would have on expected } \\
\text { quality of life as compared to now? }\end{array}$ & & & 0.74 & & & 0.97 \\
\hline Better & $23(62.2)$ & $46(63.9)$ & & $47(61.9)$ & $18(66.7)$ & \\
\hline About the same & $2(5.4)$ & $8(11.1)$ & & $8(10.5)$ & $2(7.4)$ & \\
\hline Worse & $1(2.7)$ & $2(2.8)$ & & $2(2.6)$ & $1(3.7)$ & \\
\hline Not sure & $11(29.7)$ & $16(22.2)$ & & $19(25)$ & $6(22.2)$ & \\
\hline $\begin{array}{l}\text { Did primary gastroenterologist or hepatologist } \\
\text { provide as much information about LT as desired? }\end{array}$ & & & $<0.01$ & & & 0.61 \\
\hline Yes & $35(94.6)$ & $47(65.3)$ & & $58(76.3)$ & $19(70.4)$ & \\
\hline No/Not sure & $2(5.4)$ & $25(34.7)$ & & $18(23.7)$ & $8(29.6)$ & \\
\hline Are you concerned about the financial costs of LT?* & & & 0.94 & & & 0.63 \\
\hline Very concerned & $10(27.0)$ & $17(24.0)$ & & $20(26.7)$ & $5(18.5)$ & \\
\hline Concerned & $12(32.4)$ & $27(38.0)$ & & $29(38.6)$ & $9(33.3)$ & \\
\hline Not concerned & $14(37.8)$ & $24(33.8)$ & & $23(30.7)$ & $12(44.5)$ & \\
\hline Not sure & $1(2.7)$ & $3(4.2)$ & & $3(4.0)$ & $1(3.7)$ & \\
\hline $\begin{array}{l}\text { Are you willing to travel to a transplant } \\
\text { center to be evaluated and tested? }\end{array}$ & & & 0.30 & & & 0.43 \\
\hline Very willing & $25(67.6)$ & $37(51.4)$ & & $44(57.9)$ & $15(55.6)$ & \\
\hline Willing & $12(32.4)$ & $31(43.0)$ & & $30(39.5)$ & $11(40.7)$ & \\
\hline Not willing & $0(0)$ & $4(5.6)$ & & $0(0)$ & $1(3.7)$ & \\
\hline Not sure & $0(0)$ & $0(0)$ & & $2(2.6)$ & $0(0)$ & \\
\hline $\begin{array}{l}\text { Do you understand the system by which livers } \\
\text { are distributed to patients on the waiting list?* }\end{array}$ & & & $<0.01$ & & & 0.03 \\
\hline Yes & $31(83.8)$ & $34(47.9)$ & & $48(64.0)$ & $12(44.4)$ & \\
\hline No & $0(0)$ & $30(42.2)$ & & $16(21.3)$ & $13(48.2)$ & \\
\hline Not sure & $6(16.2)$ & $7(9.9)$ & & $11(14.7)$ & $2(7.4)$ & \\
\hline Do you know what the requirements are for listing for LT? & & & $<0.01$ & & & 0.01 \\
\hline Yes & $28(75.7)$ & $30(41.7)$ & & $46(60.5)$ & $9(33.3)$ & \\
\hline No & $4(10.8)$ & $32(44.4)$ & & $19(25.0)$ & $15(55.6)$ & \\
\hline Not sure & $5(13.5)$ & $10(13.9)$ & & $11(14.5)$ & $3(11.1)$ & \\
\hline $\begin{array}{l}\text { Have you discussed the process } \\
\text { of organ distribution with a physician? }\end{array}$ & & & $<0.001$ & & & 0.14 \\
\hline Yes & $33(89.2)$ & $33(45.8)$ & & $49(64.5)$ & $12(44.4)$ & \\
\hline No & $4(10.8)$ & $36(50.0)$ & & $25(32.9)$ & $14(51.9)$ & \\
\hline Not sure & $0(0)$ & $3(4.2)$ & & $2(2.6)$ & $1(3.7)$ & \\
\hline Do you understand what MELD means and includes? & & & $<0.001$ & & & 0.04 \\
\hline Yes & $30(81.1)$ & $23(31.9)$ & & $42(55.3)$ & $9(33.3)$ & \\
\hline No & $3(8.1)$ & $39(54.2)$ & & $24(31.6)$ & $16(59.3)$ & \\
\hline Not sure & $4(10.8)$ & $10(13.9)$ & & $10(13.1)$ & $2(7.4)$ & \\
\hline $\begin{array}{l}\text { Do you feel that minorities get } \\
\text { equal access to LT compared to whites?* }\end{array}$ & & & 0.07 & & & $<0.001$ \\
\hline Yes & $14(37.8)$ & $39(54.9)$ & & $43(57.4)$ & $8(29.6)$ & \\
\hline No & $2(5.4)$ & $8(11.3)$ & & $1(1.3)$ & $8(29.6)$ & \\
\hline Not sure & $21(56.8)$ & $24(33.8)$ & & $31(41.3)$ & $11(40.8)$ & \\
\hline
\end{tabular}

NOTE: Data are given as $\mathrm{n}(\%)$.

*Missing 1 nonlisted and white patient. 
transplant center if referred (44.4\% versus $71.1 \% ; P=$ 0.02; Table 4). There were no racial differences in physicians discussing LT or the likelihood of wanting a transplant if recommended. Black patients were significantly less likely to report an understanding of the requirements for LT listing, liver organ distribution, and MELD score (Table 4). Significantly fewer black patients felt minorities had equal access to LT compared to whites $(29.6 \%$ versus $57.4 \% ; P<0.001)$.

\section{OD PREFERENCES}

Lastly, we assessed how a patient's knowledge and preferences influence his or her views about OD. Most patients had heard about OD, but unfortunately most did not indicate they would like to be an organ donor on their driver's licenses (Table 5). Despite this, the majority of nonlisted and listed patients reported being very likely or likely to donate organs upon their death (51.3\% versus $59.4 \% ; P=0.7$ ). Neither group associated OD with doctors not trying to save their lives. In order to assess potential barriers to OD, the survey asked about whether OD was against ethical/moral or religious beliefs. Very few patients reported these as potential barriers $(0.0 \%-8.3 \%)$. Neither group indicated financial incentives or being approached about donation by someone of the same cultural or ethnic background would increase donation. Family and medical professional sources influenced patient's opinions regarding OD in both groups.

Significant racial differences in preferences and perceived barriers to OD exist in our population. Significantly fewer blacks reported their driver's license indicated an intention to donate their organs $(11.1 \%$ versus $50.0 \% ; P<0.001)$ and significantly more blacks were unlikely or unsure about becoming an organ donor in the future $(55.5 \%$ versus $31.5 \% ; P=0.04$; Table 5$)$. Ethical/moral and religious beliefs did not influence OD preferences. More black patients were neutral about the role of organ donor status's impact on a doctor's willingness to save their life. Interestingly, significantly more blacks reported being more likely to become an organ donor if approached by someone of the same cultural or ethnic background (44.4\% versus $15.8 \% ; P<0.01$ ).

\section{Discussion}

Understanding how patients perceive challenges surrounding LT, their goals, and their ability to navigate obstacles helps ensure equal access across racial, gender, and geographic boundaries. This analysis assists with identifying barriers that differed between wait-listed and non-wait-listed patients as well as between races in order to develop future interventions intended to reduce disparities in access to LT in the United States.

We found that neither HCSD nor religiosity was associated with nonlisting for LT at our transplant center. Importantly, this did not differ by race. Other barriers between listed and nonlisted patients were identified, however, and included previously recognized sociodemographic factors such as lower education levels and lack of private insurance. ${ }^{(17-20)}$ Insurance has been identified as a barrier previously. Bryce et al. ${ }^{(4)}$ retrospectively followed patients through the process from hospitalization for ESLD to listing for LT in Pennsylvania. They found the process differed substantially by gender, race, and insurance. Similar to our findings, blacks were less likely to be referred for LT, and insurance status was particularly important in early access to referral and evaluation. Nguyen et al. ${ }^{(21)}$ also observed private insurance as an independent predictor of LT and referral to a transplant center in a separate study. The impact of the Affordable Care Act on access to LT will be important to assess in the future, as insurance status is a potentially modifiable barrier. The hope is that with improved coverage LT could be more easily achieved.

Lower education and decreased access to transplantation has been documented in kidney and lung transplantation literature previously. Results suggest that educational attainment may influence access beyond its role as a sociodemographic characteristic. ${ }^{(22-24)}$ Most patients desired information regarding LT; thus, it is possible that education level may have impacted a patient's ability to understand or remember these discussions with physicians. Education and health care literacy may have influenced a physician's willingness to have these discussions with patients in the first place. Although we could not determine this kind of detail from our study, educational level is a modifiable barrier. These data suggest providers should embrace educational and health care literacy initiatives designed to overcome such obstacles and improve access to transplantation. Race may have influenced our findings because there were more white patients listed for LT and whites were significantly more likely to have college degrees and private insurance.

Listing for LT may also involve other socioeconomic factors such as the ability to travel or income. Our data, however, indicate that these were not significant factors given similar household incomes, travel distances, and methods of transportation between both listed 
TABLE 5. Knowledge and Patient Preferences on OD

\begin{tabular}{|c|c|c|c|c|c|c|}
\hline & \multicolumn{3}{|c|}{ Group } & \multicolumn{3}{|c|}{ Race } \\
\hline & $\begin{array}{l}\text { Listed Patients } \\
\quad(\mathrm{n}=37)\end{array}$ & $\begin{array}{c}\text { Nonlisted Patients } \\
(\mathrm{n}=72)\end{array}$ & $P$ Value & $\begin{array}{c}\text { White } \\
(n=76)\end{array}$ & $\begin{array}{c}\text { Black } \\
(n=27)\end{array}$ & $P$ Value \\
\hline Have you heard about OD? & & & 1.0 & & & 0.26 \\
\hline Yes & $37(100)$ & $71(98.6)$ & & $76(100)$ & $26(96.3)$ & \\
\hline No & $0(0)$ & $1(1.4)$ & & $0(0)$ & $1(3.7)$ & \\
\hline $\begin{array}{l}\text { Does your driver's license indicate that you would like to be } \\
\text { an organ donor? }\end{array}$ & & & 0.50 & & & $<0.001$ \\
\hline Yes & $15(40.5)$ & $28(38.9)$ & & $38(50.0)$ & $3(11.1)$ & \\
\hline No & $21(56.8)$ & $37(51.4)$ & & $33(43.4)$ & $21(77.8)$ & \\
\hline Not sure & $1(2.7)$ & $7(9.7)$ & & $5(6.6)$ & $3(11.1)$ & \\
\hline $\begin{array}{l}\text { How likely are you to have your organs donated upon your } \\
\text { death? }\end{array}$ & & & 0.70 & & & 0.51 \\
\hline Very likely & $14(37.8)$ & $23(31.9)$ & & $26(34.2)$ & $10(37.0)$ & \\
\hline Likely & $8(21.6)$ & $14(19.4)$ & & $14(18.4)$ & $4(14.8)$ & \\
\hline Neutral & $5(13.5)$ & $13(18.1)$ & & $13(17.1)$ & $4(14.8)$ & \\
\hline Unlikely & $3(8.1)$ & $12(16.7)$ & & $13(17.1)$ & $2(7.4)$ & \\
\hline Very unlikely & $7(19.0)$ & $10(13.9)$ & & $10(13.2)$ & $7(26)$ & \\
\hline $\begin{array}{l}\text { Would you like to be an organ donor if you are not one } \\
\text { currently? }\end{array}$ & & & 0.40 & & & 0.04 \\
\hline Yes & $9(24.3)$ & $16(22.2)$ & & $17(22.4)$ & $7(26)$ & \\
\hline No & $9(24.3)$ & $15(20.8)$ & & $16(21.0)$ & $8(29.5)$ & \\
\hline Not sure & $3(8.1)$ & $15(20.8)$ & & $8(10.5)$ & $7(26)$ & \\
\hline Not applicable & $16(43.3)$ & $26(36.2)$ & & $35(46.0)$ & $5(18.5)$ & \\
\hline $\begin{array}{l}\text { If doctors know I am an organ donor, they won't try to save } \\
\text { my life. }\end{array}$ & & & 0.14 & & & 0.01 \\
\hline Strongly agree & $0(0)$ & $0(0)$ & & $0(0)$ & $0(0)$ & \\
\hline Agree & $0(0)$ & $1(1.4)$ & & $0(0)$ & $1(3.7)$ & \\
\hline Neutral & $5(13.5)$ & $12(16.7)$ & & $6(7.9)$ & $7(26)$ & \\
\hline Disagree & $23(62.2)$ & $29(40.3)$ & & $37(48.7)$ & $13(48.1)$ & \\
\hline Strongly disagree & $9(24.3)$ & $30(41.6)$ & & $33(43.4)$ & $6(22.2)$ & \\
\hline $\begin{array}{l}\text { Is it against your ethical or moral beliefs to donate your } \\
\text { organs? }\end{array}$ & & & 0.40 & & & 0.16 \\
\hline Yes & $1(2.7)$ & $6(8.3)$ & & $3(4.0)$ & $3(11.1)$ & \\
\hline No & $36(97.3)$ & $64(88.9)$ & & $72(94.7)$ & $23(85.2)$ & \\
\hline Not sure & $0(0)$ & $2(2.8)$ & & $1(1.3)$ & $1(3.7)$ & \\
\hline Is it against your religious beliefs to donate your organs? & & & 0.46 & & & 1.00 \\
\hline Yes & $0(0)$ & $3(4.2)$ & & $2(2.6)$ & $1(3.7)$ & \\
\hline No & $36(97.3)$ & $64(88.9)$ & & $69(90.8)$ & $25(92.6)$ & \\
\hline Not sure & $1(2.7)$ & $5(6.9)$ & & $5(6.6)$ & $1(3.7)$ & \\
\hline $\begin{array}{l}\text { Do you believe that people/families who donate organs should } \\
\text { receive money for donating?* }\end{array}$ & & & 0.44 & & & 0.05 \\
\hline Yes & $3(8.1)$ & $5(7.1)$ & & $3(4.0)$ & $5(18.5)$ & \\
\hline No & $23(62.2)$ & $52(73.2)$ & & $54(72)$ & $17(63.0)$ & \\
\hline Not sure & $11(29.7)$ & $14(19.7)$ & & $18(24)$ & $5(18.5)$ & \\
\hline $\begin{array}{l}\text { Do you think it is important to have a legal binding document } \\
\text { indicating your wishes for OD upon your death? }\end{array}$ & & & 1.00 & & & 0.14 \\
\hline Yes & $27(73)$ & $50(69.5)$ & & $57(75)$ & $17(63.0)$ & \\
\hline No & $7(18.9)$ & $15(20.8)$ & & $16(21)$ & $6(22.2)$ & \\
\hline Not sure & $3(8.1)$ & $7(9.7)$ & & $3(4)$ & $4(14.8)$ & \\
\hline $\begin{array}{l}\text { Do you think you would be more likely to become an organ } \\
\text { donor if someone of the same cultural or ethnic background } \\
\text { approached you about the process? }\end{array}$ & & & 0.39 & & & $<0.01$ \\
\hline Yes & $7(18.9)$ & $17(23.6)$ & & $12(15.8)$ & $12(44.4)$ & \\
\hline No & $26(70.3)$ & $52(72.2)$ & & $58(76.3)$ & $15(55.6)$ & \\
\hline Not sure & $4(10.8)$ & $3(4.2)$ & & $6(7.9)$ & $0(0)$ & \\
\hline $\begin{array}{l}\text { Which of the following sources would most likely influence the } \\
\text { way you feel about OD? }\end{array}$ & & & 0.12 & & & 0.06 \\
\hline Family & $10(27.0)$ & $32(44.4)$ & & $33(43.4)$ & $7(26)$ & \\
\hline Friends & $0(0)$ & $1(1.4)$ & & $0(0)$ & $1(3.7)$ & \\
\hline Medical professional & $13(35.3)$ & $13(18.1)$ & & $20(26.3)$ & $5(18.5)$ & \\
\hline Member of a religious organization & $1(2.7)$ & $7(9.7)$ & & $3(40)$ & $4(14.8)$ & \\
\hline
\end{tabular}


TABLE 5. Continued

\begin{tabular}{|c|c|c|c|c|c|c|}
\hline & \multicolumn{3}{|c|}{ Group } & \multicolumn{3}{|c|}{ Race } \\
\hline & $\begin{array}{l}\text { Listed Patients } \\
\quad(n=37)\end{array}$ & $\begin{array}{c}\text { Nonlisted Patients } \\
\quad(\mathrm{n}=72)\end{array}$ & $P$ Value & $\begin{array}{c}\text { White } \\
(n=76)\end{array}$ & $\begin{array}{c}\text { Black } \\
(n=27)\end{array}$ & $P$ Value \\
\hline Newspaper & $2(5.4)$ & $2(2.8)$ & & $4(5.3)$ & $0(0)$ & \\
\hline Internet & $0(0)$ & $1(1.4)$ & & $1(1.3)$ & $0(0)$ & \\
\hline Movies & $1(2.7)$ & $0(0)$ & & $0(0)$ & $0(0)$ & \\
\hline Other & $10(27.0)$ & $16(22.2)$ & & 15 (19.7) & 10 (37) & \\
\hline
\end{tabular}

NOTE: Data are given as $\mathrm{n}(\%)$.

*Missing 1 nonlisted white patient.

and nonlisted patients and between blacks and whites. Employment status was significantly different in the univariate analyses, however, and this could have impacted a patient's ability to access appropriate medical insurance and/or financial support for LT. Medical and social reasons may have also affected discussion of LT and referral. A perceived inability to meet requirements due to lack of social support, ongoing tobacco or alcohol use, or comorbid illness may have prevented discussions regarding LT or referral to the transplant center. Patients may also not recall these conversations with their providers, resulting in recall bias.

One could argue, however, that many of these barriers should not limit LT discussions and could in fact help a patient overcome obstacles to listing for LT. Unfortunately, we could not assess the interaction of these patient-related characteristics with discussion or referral patterns. If a provider was not willing to discuss a patient's preferences for LT, the patient's options may have been limited beyond their control. Previous studies do support an impact of practice variation in physician referral patterns on LT access. ${ }^{(25)}$ Disparity by education or race may be further exacerbated if certain minority groups are less likely to be seen in health centers where providers are knowledgeable about LT and associated resources.

Future research should seek to improve provider communication skills (especially culturally appropriate communication), education regarding the need to discuss LT with all patients meeting minimal listing requirements, referral to an experienced hepatologist, and methods to overcome possible referral bias. In addition to improving patient-provider education, transplant hepatologists can assist with addressing deficiencies in the process by educating gastroenterologists and general hepatologists about the process of LT referral, wait-listing, liver organ allocation, and the timing and requirements for each step. Continuing medical education activities would be an easy way to improve provider understanding. At the same time, community and educational forums could improve patient education regarding LT and OD and empower those patients to gain access to their health care needs.

Overall donor availability is projected to significantly diminish over the next 15 years. Given the already inadequate $\mathrm{OD}$ rates, emphasis on how to improve donation opportunities, awareness, and practices are paramount. We found that many patients did not indicate an intention to donate organs on their driver's license despite a reported interest in OD. Although our results could not pinpoint exact reasons for this, neither moral nor religious beliefs seemed to motivate those preferences in our population. Interestingly, several patients with chronic hepatitis $\mathrm{C}$ virus indicated that they thought viral hepatitis was a contraindication to OD. Similar to previous reports, we found that blacks were less likely to want to become an organ donor than whites. ${ }^{(26)}$ This disparity was also not a result of religious or moral beliefs. Significantly more black patients reported an increased willingness to donate if approached by someone of the same race. Racial concordance is known to impact authorization for donation and underscores the importance of a diverse health care workforce. ${ }^{(27)}$

The precise etiology behind racial disparities in OD remains unclear. Education, chronic illness, and/or lack of understanding about how organs are distributed to wait-listed patients may contribute. ${ }^{(28)}$ Perceived inequality in access to organs may decrease willingness to donate among African Americans. Respecting cultural and language nuances and expectations are critical to the success of LT and OD. Workforce diversity, training, and education are vital to transforming misconceptions regarding LT and OD. Fear about premature determination of death and perceived racial inequality need to be addressed.

Trust in the medical system is considered a contributor to disparities in LT and OD. Our data suggest that this is not the case at least at our medical center. Important disparities in access, however, continue to 
exist and interventions should focus on patient and provider education, adequate health insurance coverage for all, and communication with patients and families about the process of LT and OD. Local and national policy initiatives to improve education about ESLD, the process of $\mathrm{OD}$, and access to the waiting list prior to LT could help inform patients about what to expect from providers regarding care of ESLD, foster more effective patient-physician relationships, and improve referral rates to a hepatologist and/or transplant center.

The strengths of this analysis are its unique focus on characterizing patient preferences and concerns as etiologies of disparities in LT as well as recruitment of listed and nonlisted patients from a large, diverse transplant center. Patient preference can be difficult to quantify; therefore, we used several validated questionnaires as part of our survey. Our study also has several limitations. First, telephone-based questionnaire studies are always subject to sampling and participation biases. This reflects patients' willingness to participate in surveys and whether or not they have a working phone allowing them to be considered for participation in the first place. Patients unwilling to participate may be more likely to distrust the health care system and, thus, bias our results. We attempted to overcome some of this bias by also conducting the study in outpatient clinics as well as sampling across all patient demographics. Second, the study was small and single-centered. Findings therefore may not be generalizable to patients of different backgrounds or to patients in other geographic regions around the United States. The small size also limited our ability to perform multivariate analysis for preferences and knowledge regarding LT while controlling for sociodemographic variables that may impact those preferences. The transplant center is large and diverse, however, which may help to alleviate some of this limitation, but a larger, multicenter study would need to be conducted to fully control for all variables. Third, we did not assess the time since diagnosis of liver failure. This could bias results if a patient was very recently felt to be in need of LT but had not discussed this with their physician or been referred. We were not able assess for certain absolute contraindications to LT such as significant cardiopulmonary disease or uncontrolled substance abuse. These may have led to lack of provider discussion or referral and could have led to bias in our results. We would argue, however, that it is important to capture these people as nonlisted, given that all patients who desire a discussion about options for their ESLD including a discussion about LT should have that opportunity. Perhaps a discussion would help patients change behaviors or improve their health so that they could become LT candidates in the future. Further study regarding how such interventions might impact listing should be considered. Recall bias is always of concern in questionnaire research and can lead to systematic errors in responses. For example, there may have been confusion about the definition of a transplant center. Patients unaware that Duke is a transplant center may have reported incorrectly on whether or not they were referred. Similarly, if patients received the majority of their health care at Duke University already, they may have responded no to the question of referral. The use of several questionnaires not previously validated may limit the study. Nevertheless, our findings contribute to the extremely small body of research regarding the impact of patient preferences on access to LT. Our findings can guide strategies to address barriers to access, to provide background for further investigations in this area, and to advocate for additional services to assist the growing patient population with ESLD.

In summary, this study was designed to improve understanding about patient preferences concerning LT and $\mathrm{OD}$ and the impact that religious beliefs, trust in the health care system, and knowledge of the process may have on those preferences. A particular emphasis was placed on exploring knowledge of the LT process with the goal of identifying modifiable characteristics impeding individuals in need of LT from gaining access. Patients at our center expressed a desire for better education regarding the process of LT and OD. Decisions to pursue LT as a treatment for ESLD do not appear to be influenced by distrust in the health care system or religiosity but more so by education, insurance status, and a sense of participation in the process. Importantly, much of the racial disparity seen here could also be addressed through education. Future work to develop validated, culturally and racially appropriate education and communication tools for patients and providers may aid in improving access to LT for all.

Acknowledgment: We thank Rahila Andrews for her assistance with patient enrollment.

\section{REFERENCES}

1) Scaglione $S$, Kliethermes $S$, Cao G, Shoham D, Durazo R, Luke A, Volk ML. The epidemiology of cirrhosis in the United States: a population-based study. J Clin Gastroenterol 2015;49: 690-696.

2) Kim WR, Smith JM, Skeans MA, Schladt DP, Schnitzler MA, Edwards EB, et al. OPTN/SRTR 2012 annual data report: liver. Am J Transplant 2014;14(suppl 1):69-96.

\section{4 | ORIGINAL ARTICLE}


3) Adler JT, Dong N, Markmann JF, Schoenfeld D, Yeh H. Role of patient factors and practice patterns in determining access to liver waitlist. Am J Transplant 2015;15:1836-1842.

4) Bryce CL, Angus DC, Arnold RM, Chang CC, Farrell MH, Manzarbeitia C, et al. Sociodemographic differences in early access to liver transplantation services. Am J Transplant 2009;9: 2092-2101.

5) Moylan CA, Brady CW, Johnson JL, Smith AD, TuttleNewhall JE, Muir AJ. Disparities in liver transplantation before and after introduction of the MELD score. JAMA 2008;300: 2371-2378.

6) Mathur AK, Schaubel DE, Gong Q, Guidinger MK, Merion RM. Sex-based disparities in liver transplant rates in the United States. Am J Transplant 2011;11:1435-1443.

7) Julapalli VR, Kramer JR, El-Serag HB; for American Association for the Study of Liver Diseases. Evaluation for liver transplantation: adherence to AASLD referral guidelines in a large Veterans Affairs center. Liver Transpl 2005;11:1370-1378.

8) Mathur AK, Ashby VB, Fuller DS, Zhang M, Merion RM, Leichtman A, Kalbfleisch J, et al. Variation in access to the liver transplant waiting list in the United States. Transplantation 2014;98:94-99.

9) Volk ML, Choi H, Warren GJ, Sonnenday CJ, Marrero JA, Heisler M. Geographic variation in organ availability is responsible for disparities in liver transplantation between Hispanics and Caucasians. Am J Transplant 2009;9:2113-2118.

10) Mathur AK, Sonnenday CJ, Merion RM. Race and ethnicity in access to and outcomes of liver transplantation: a critical literature review. Am J Transplant 2009;9:2662-2668.

11) Eckhoff DE, McGuire BM, Young CJ, Sellers MT, Frenette LR, Hudson SL, et al. Race: a critical factor in organ donation, patient referral and selection, and orthotopic liver transplantation? Liver Transpl Surg 1998;4:499-505.

12) Ayanian JZ, Cleary PD, Weissman JS, Epstein AM. The effect of patients' preferences on racial differences in access to renal transplantation. N Engl J Med 1999;341:1661-1669.

13) Maynard C, Fisher LD, Passamani ER, Pullum T. Blacks in the coronary artery surgery study (CASS): race and clinical decision making. Am J Public Health 1986;76:1446-1448.

14) Mazzaferro V, Regalia E, Doci R, Andreola S, Pulvirenti A, Bozzetti $\mathrm{F}$, et al. Liver transplantation for the treatment of small hepatocellular carcinomas in patients with cirrhosis. N Engl J Med 1996;334:693-699.

15) Rose A, Peters N, Shea JA, Armstrong K. Development and testing of the health care system distrust scale. J Gen Intern Med 2004;19:57-63.
16) Sherman AC, Plante TG, Simonton S, Adams DC, Harbison C, Burris SK. A multidimensional measure of religious involvement for cancer patients: the Duke religious index. Support Care Cancer 2000;8:102-109.

17) Barritt AS 4th, Telloni SA, Potter CW, Gerber DA, Hayashi $\mathrm{PH}$. Local access to subspecialty care influences the chance of receiving a liver transplant. Liver Transpl 2013;19:377-382.

18) Kemmer N, Zacharias V, Kaiser TE, Neff GW. Access to liver transplantation in the MELD era: role of ethnicity and insurance. Dig Dis Sci 2009;54:1794-1797.

19) Rivera MN, Jowsey S, Alsina AE, Torres EA. Factors contributing to health disparities in liver transplantation in a Hispanic population. P R Health Sci J 2012;31:199-204.

20) Tuttle-Newhall JE, Rutledge R, Johnson M, Fair J. A statewide, population-based, time series analysis of access to liver transplantation. Transplantation 1997;63:255-262.

21) Nguyen GC, Segev DL, Thuluvath PJ. Racial disparities in the management of hospitalized patients with cirrhosis and complications of portal hypertension: a national study. Hepatology 2007; 45:1282-1289.

22) Salter ML, Gupta N, King E, Bandeen-Roche K, Law AH, McAdams-DeMarco MA, et al. Health-related and psychosocial concerns about transplantation among patients initiating dialysis. Clin J Am Soc Nephrol 2014;9:1940-1948.

23) Goldfarb-Rumyantzev AS, Sandhu GS, Baird B, Barenbaum A, Yoon JH, Dimitri N, et al. Effect of education on racial disparities in access to kidney transplantation. Clin Transplant 2012; 26:74-81.

24) Quon BS, Psoter K, Mayer-Hamblett N, Aitken ML, Li CI, Goss CH. Disparities in access to lung transplantation for patients with cystic fibrosis by socioeconomic status. Am J Respir Crit Care Med 2012;186:1008-1013.

25) Pidala J, Craig BM, Lee SJ, Majhail N, Quinn G, Anasetti C. Practice variation in physician referral for allogeneic hematopoietic cell transplantation. Bone Marrow Transplant 2013;48: 63-67.

26) Goldberg DS, Halpern SD, Reese PP. Deceased organ donation consent rates among racial and ethnic minorities and older potential donors. Crit Care Med 2013;41:496-505.

27) Bodenheimer HC Jr, Okun JM, Tajik W, Obadia J, Icitovic N, Friedmann $\mathrm{P}$, et al. The impact of race on organ donation authorization discussed in the context of liver transplantation. Trans Am Clin Climatol Assoc 2012;123:64-77.

28) Siminoff LA, Burant CJ, Ibrahim SA. Racial disparities in preferences and perceptions regarding organ donation. J Gen Intern Med 2006;21:995-1000. 